- A series of focus groups were performed to investigate perspectives and motivations relating to the introduction of the 'new ways of working.'

- Some dental practitioners relayed dissatisfaction with the clarity of information provided by the Government in relation to the details of the new contract.

- The resulting uncertainty makes it difficult for GDPs to plan future practice activity and commitment to NHS dentistry.

- There is a strong need for communication, information and openness between the Government, PCTs and GDPs during this period of organisational change.

- Support and guidance for GDPs are crucial.

\title{
Perspectives of dentists in primary care ahead of the 'new ways of working'
}

\author{
W. O. Baird, ${ }^{1}$ R. J. Jackson, ${ }^{2}$ L. S. Worthington ${ }^{3}$ and P. G. Robinson ${ }^{4}$
}

Objective To determine the future intentions and motivations of general dental practitioners (GDPs) relating to NHS dental practice in South Yorkshire.

Design Focus group discussions.

Setting General dental practices providing NHS care within South Yorkshire, United Kingdom.

Subjects (materials) and methods Twenty-nine dental practitioners were purposively sampled and invited to take part in a series of focus groups. Focus groups were transcribed and data analysed to identify themes and concepts.

Main outcome measures Themes and concepts relating to the current and future provision of dentistry and the proposed 'new ways of working' of the new dental contract.

Results The data fell into three broad categories: the organisational structures of dentistry; the future of dentistry; and the CDS. This paper focuses largely on the second category, the future of NHS dentistry. The first category related to the organisational structures of dentistry, and encompassed perceptions that dentistry was not a high priority for the Government and that current changes were politically motivated and to be implemented by PCTs with a lack of capacity for the management of such wide-reaching changes. The second category covered the future of NHS dentistry. For some, NHS dentistry was in a precarious and uncertain position, coupled with a lack of clarity and information on the 'new ways of working' and exacerbated by problems in the recruitment and retention of future dental practitioners. The last category dealt with views in connection with the CDS.

\footnotetext{
$1^{1 *}$ Lecturer in Health Services Research, ${ }^{2}$ Research Associate, Section of Public Health, ScHARR, University of Sheffield, Regent Court, 30 Regent Street, Sheffield, S1 4DA; ${ }^{3}$ Associate Postgraduate Dental Dean, South Yorkshire Strategic Health Authority, Don Valley House, Savile Street East, Sheffield, S4 7UQ; ${ }^{4}$ Professor of Dental Public Health, Department of Oral Health and Development, 1st Floor, School of Clinical Dentistry, University of Sheffield, Claremont Crescent, Sheffield, S10 2TA ${ }^{*}$ Correspondence to: Dr Wendy Baird

Email:w.o.baird@sheffield.ac.uk
}

\section{Online article number E24}

Refereed Paper - accepted 12 June 2006

DOI: $10.1038 /$ bdj.2007.270

${ }^{\circledR}$ British Dental Journal 2007; 202: E24
Conclusion(s) In this 'snapshot in time' there was considerable uncertainty and instability within the general dental service against a backdrop of major organisational change. There was a need for information, guidance, openness and communication between the Government, PCTs and GDPs surrounding the implementation of the new contract.

\section{INTRODUCTION}

A series of proposals by the Chief Dental Officer provided Options for change to reconfigure primary dental care in England. ${ }^{1}$ These proposals were largely adopted in the Health and Social Care Act that required primary care trusts (PCTs) to commission oral healthcare for their populations from April 2005. ${ }^{2}$ The new working arrangements were rescheduled for October 2005 but implementation eventually took place in April 2006. ${ }^{3,4}$

Fundamental to the introduction and stability of the new system were the new contractual arrangements between PCTs and primary care dentists. This was to be based on the Personal Dental Services (PDS) contracts, developed jointly with the British Dental Association (BDA). Progress has not been rapid but the base contract aimed to offer financial security to practices as gross earnings would be guaranteed for three years, provided the practice continued to provide the same degree of NHS commitment. In order to progress, PCTs offered dentists PDS contracts, to enable them to move to local contracts ahead of the national base contract.

In the meantime, the National Audit Office reported that, whilst there was a need for reform in NHS dentistry, 'significant risks would need to be managed if new systems were to be effective and provide value for money. ${ }^{5}$ Dentists have been apprehensive because they perceive that the GDS has been under-funded for some time. Anecdotally, these anxieties are fuelled because GDPs do not understand how Options for Change will affect them.

The BDA commissioned a survey of its members in the early spring of $2004 .{ }^{6}$ Only 30\% of those sampled responded and so it is likely that the findings over-represent dentists with 


\section{Fig. 1 Characteristics of focus group participants}

- Senior LDC members / Senior CDS members

- Senior practice principals

- Members of established practitioner groups

- Single-handed practitioners

- Associates

- Vocational trainees

strong feelings. However, only 21\% of respondents thought that the new contract would improve their working life and $60 \%$ thought the proposals would not benefit patients. Only $10 \%$ of respondents thought PCTs could manage the change to the new contracts.

It was against this backdrop that this study aimed to gain an insight into the future expectations and intentions of the South Yorkshire dentists.

\section{METHODS}

Twenty nine dental professionals (24\% female) who were purposively sampled took part in a series of focus groups in order to further explore the intentions and motivations of the primary dental workforce in South Yorkshire (Fig. 1). Purposive sampling is used to make sure that a wide variety of views is captured, is useful in the exploration of new topics and maximises the development of emergent hypotheses through group interactions generating a large amount of rich data. ${ }^{7,8}$ Recruitment was from records held by local PCTs and via direct personal contact. The focus groups were held between 0ctober 2004 and January 2005, at a time when some practitioners participating had already moved to PDS contracts. Each focus group lasted 1.5-2.5 hours and consisted of between three and eight dental professionals. Focus groups were held at informal locations in Sheffield and Rotherham.

A preliminary topic guide was devised using the insights of a multidisciplinary collaborative group, a review of the pertinent literature and the responses to the open questions in a questionnaire based study. The first author, who is trained in qualitative methodology, used the topic guide to direct the content of all focus groups. The initial areas of investigation included for example, the dental workforce, the new dental contract and the future of dentistry in the NHS. However, this was supplemented as new themes arose in each group.

The focus groups were audio-taped and transcribed verbatim. Using the constant comparative method, data collection and analysis occurred concurrently. ${ }^{9}$ Emergent themes from earlier focus groups were explored in subsequent focus groups until saturation occurred. At the end of each focus group, the discussion was reviewed by the researcher and participants to ensure the results were compatible with the primary data.

Similar excerpts from the transcripts were grouped together (coded by themes) and these groups were drawn together into broadly related categories. This process was repeated until no new groups could occur. ${ }^{10,11}$

The data and analysis were reviewed by the research team and advisors at different stages to ensure minimal interpretation and bias. The fourth author reviewed the processes involved at all stages; from data collection, interim analysis and final analysis in light of the previous stages. Furthermore, the findings were triangulated by comparison of the quantitative data and the qualitative data collected in the questionnaire based study and focus groups. Whilst the responses to open questions in the questionnaire were naturally more restricted than those collected in focus groups, they were broadly compatible. A draft of the findings was sent out for consultation to research participants, advisors and to the following key players in South Yorkshire: the Chairs of all three Local Dental Committees, to Mr Derek Thomson (Acting Dental Lead for the Strategic Health Authority) and to the two Directors of Dental Public Health.

\section{RESULTS}

The qualitative data fell into three major categories. The first category refers to the organisational structures of dentistry but particularly relates to how participants felt these structures interacted. The second category considered threats to NHS dentistry, the impact of the new ways of working and participants' suggestions for the way ahead. These two categories emerged in the data analysis and allow an understanding of the data, however they are not identified by participants but arise from data analysis. Nor are the categories separate and mutually exclusive as there are both overlaps and interrelations between them. A final relatively discrete category deals largely with the concerns and perspectives of the CDS. Other than setting the scene for the findings, this paper reports mainly on the second category, the future of NHS dentistry.

\section{Organisational structures of dentistry}

Dentistry was widely felt not to be a high priority for the Government and PCTs. Many dentists recognised a strong political motivation behind attempts to improve access by the introduction of the new contract. The current focus on NHS dentistry was felt to reflect a political desire to alleviate pressure caused by high profile access problems and public and media concern. For example, a perceived lack of capacity within PCTs was attributed to the PCT not considering dentistry in the normal course of events: '...dentistry just never hits the horizon' (CDS staff,
November 2004).

It was argued that the Government had a responsibility to clarify the position of dentistry within the NHS. For some this argument included whether they wanted 'quality or quantity' (Principal partner, January 2005).

\section{The future of NHS dentistry}

Challenges to NHS dentistry included private dentistry, workforce shortages and the lack of a career structure. Some dentists saw the future to be dominated by private dentistry, whereas others saw a continued role for the NHS. Even the most ardent supporters of private care recognised a role for the NHS.

One view was that NHS dentistry could only exist in the future if a core service was provided offering essential items such as check ups and fillings to all. Patients would pay for more expensive treatments such as crown and bridgework. Related to this view was that it was not possible to provide a comprehensive service to the entire population. These dentists nonetheless recognised that their ideal situation of a 
core service would not be popular with either the patients or the Government. Some felt that the Government would have to take responsibility for a core service as that is what PDS would become.

'I think the Government have got a perfect opportunity to be absolutely honest with us and the general public and say, okay we haven't got stacks of money that we can throw at NHS dentistry... they say, this is what we will provide, then everybody knows exactly where we are' (Principal partner, January 2005).

Some dentists resented that even in the heartland of the NHS' (Dental management, November 2004), they were being given no choice but to convert to a private practice and that the Government would assign the blame for that to the dentists. The option to convert to private care was the ultimate survival strategy were PDS to fail, as 'more and more practices will just say forget it then' (Single-handed practitioner, December 2004).

Some cited the shortfall in dentists in the UK as another reason for the existing problems in dentistry and this factor alone determined the ability of dental services to change in the long term. The ability to recruit new dentists was an issue for seemingly all participants. It was also suggested that the NHS dental workforce in South Yorkshire was aging, which would place further demands on recruitment. It was felt that the reluctance of young dentists to take on the responsibility of running a practice would also alter the infrastructure of dentistry in the long term.

\section{The new ways of working}

A frequent view held that the initial components of the new contract had been 'all things to all people' which had aimed to encourage dentists to provide dentistry the way they felt was appropriate for their patients in a 'high trust environment' (Single-handed practitioner, December 2004).

'The new system encourages you... to treat them how you want to treat them, rather than the only way that you could' (Principal practitioner, January 2005).

Some dentists recognised that one improvement could be stability in income, even if only for three years, which was seen by some as an improvement on fee per item income. For others this level of stability was inadequate.

'...you can't make a one, two, five year plan of where you are going to be and how much money you are going to put into the practice, for new equipment and so on, because you have no idea what the PCT are going to offer you' (Single-handed practitioner, December 2004).

There was also a feeling that many of the original principles had already been 'watered down' (Principal practitioner, January 2005) and that the Government was backtracking. The new contract would tie practitioners to the NHS for the next three years and the bonus would be six weeks paid holidays a year, therefore working conditions were better for dentists but this had been at the expense of the care for patients.

'I think the Government doesn't know a great deal about dentistry... I'm not being cynical there, they have paid for the service, the service happens, happens because it happened through independent contractors on a national basis since 1948, and I really don't think the Government knows where it needs dentists, it knows that people can't get a dentist but it doesn't know how its going to reorganise dentists, so it's given this, the PCTs the problem' (Principal practitioner, November 2004).

Another concern was that the new ways of working, which had been developed to increase access, might reduce overtreatment but would not benefit patients or improve dentistry as the increased access would only be for temporary treatment. This view held that it was not possible to provide full treatment for everyone as the new ways of working would 'encourage dentists to keep the same number of courses of treatment'.

'I don't see how it's making dentistry more available to Joe Public at all' (Principal partner, November 2004).

Whilst many dentists were in favour of the stability of a known income for three years as this would enable them to make some short-term plans for their business, a major concern was clinical freedom and control of running the business. The stability of income brought about by the new ways of working would restrict flexibility. It would prevent dentists being able to work hard over longer hours to increase income, particularly at the outset of one's career to help with the expense of student debts and property prices. Seen in this way the new ways of working posed a threat to independence. Some dentists were reluctant to give this control to the Government or PCTs.

'It [the new contract]... limits your prescription as a dentist... you're toeing the practice line and there is a certain budget for crown and bridge work in that practice... whereas if you're, if you have a private contract with the PCT then you can make that decision for yourself... it is severely limiting the way you operate and everyone operates differently, and they're trying to create a population of average dentists and there is no average dentist out there, every dentist works in a unique way to them.' (Vocational trainee, October 2004).

There was one other concern about the new ways of working, held even by those who had adopted them. As yet, patients may be unaffected by the transition, but they may be sensitive to possible increases in waiting times and fee scales in the future and dentists would bear the brunt of any dissatisfaction. Therefore, a degree of uncertainty existed concerning their future.

\section{Uncertainty}

Whilst there were some expressions of satisfaction with the help received from local PCTs, many dentists displayed considerable uncertainty in relation to the changes and cited a perceived lack of information as a cause of uncertainty in how to plan for the future. Dentists described facing important changes concerning their business without explicit information. The organisations held responsible for this lack of information were the Government, Department of Health and PCTs. In some cases delays by the Government in providing information and implementing change exacerbated mistrust and speculation.

'You wonder why is it getting delayed, why haven't they released figures? You know. It just seems a bit indecisive, we're all kept in the dark, but the longer you keep them in the dark, the more people make speculation.' (Vocational trainee, October 2004). 
'I have no complaints about $X$ and $Y$, they [PCT staff] seem to know exactly what they are doing' (Single-handed practitioner, November 2004).

In some cases there was a fear of deception, but others felt that the authorities handling negotiations were also in the dark and lacked a strategy.

'They're acting out of ignorance, if you see what I mean... they don't know.' (Senior LDC, November 2004).

\section{What is appropriate?}

One specific area of uncertainty was one of 'What is appropriate?' What clinical work would be expected and classed as appropriate treatment in the future? There was a wish for more information concerning the complexity of work to be covered so that dentists could plan their activities and inform patients. Coupled with this was a perceived lack of clarity about the targets and expectations of productivity that PCTs might have.

This core uncertainty had implications beyond the future monitoring of practices. Dentists were concerned about difficulties in maintaining productivity levels and prescribing profiles (especially for treatments involving laboratory fees) and whether failure to achieve expected productivity levels would affect the value of future contracts should they fail to reach the 'as yet unknown' criteria.

'Where are those boundaries? What makes them up? I have no idea.' (Vocational trainee, October 2004).

'...their whole argument was going to get rid of the treadmill, but they can't do that, so there needs to be trust on both sides and is that going to happen?' (Vocational trainee, October 2004).

'I think they should treat us as a profession, they should trust us and let us get on with it, but the trouble is, I know why they won't, it's because there is such a load of robbing dogs in the game... but they don't do anything about them' (Principal practitioner, January 2005).

There were also mixed feelings about the various monitoring methods to be implemented. A particular concern was that a new treadmill may prevent improved working conditions. Activities such as preventive measures and involvement in CPD that could not be easily measured were also regarded as a potential threat.

\section{Negotiating the contract value}

Narratives about contract negotiations varied widely. Some variations were related to geographical differences. Others referred to local variations in the knowledge, amount of information, the process and the funds available. Some practitioners had straightforward contract negotiations based on their previous income, whereas others reported that the PCT 'seemed to change their ideas on the amount of money they were going to offer us' (Principal associate, November 2004).

Negotiating for the contract had been easy for some: 'anybody who has gone into a PDS contract seems to be doing remarkably well, remarkably well' (Dental management, November 2004). Others observed that some dentists had transferred to new contracts but had only been remunerated accordingly, with no contract provided. Dentists who made these observations felt PCTs were ill prepared due to a lack of guidance from the Department of Health.

Some participants stressed the need for flexibility in future contracts and anticipated a resistance to a 'one size fits all' approach that could not be adapted to individual circumstances. Several were anxious about future negotiations with the PCTs and resented this element of control that could decide whether or not their business expanded. Similarly, it was felt that these types of negotiations would inhibit practitioners who might work at one practice and who might consider working at another.

\section{8}

On the basis of experiences of negotiations, some dentists had formed the view that the implementation of the changes would have 'a catch', possibly resulting in failure to fulfil the founding principles of the contract. Some felt that the new arrangements would not be permanent and consequently lacked faith in their success. Typically these dentists believed that difficulties would arise in three years on renegotiation and when calculations for expected treatments and new patient charges would create problems.

'I think, I think, people will take contracts and I don't think the time bomb's now, it's when the PCT turn round to you, like you said you haven't performed to, and then it'll be a case of, 'well you don't like it, I'm away” (Principal practitioner, January 2005).

'I think we are fooling ourselves if we think we are going to get the same money in three years time, we won't I know that, unless you provide a lot more services.' (Single-handed practitioner, November 2004).

'...three to six years time, NHS dentistry is either going to sort itself out or it's going to die a death' (Vocational trainee, October 2004).

Some dentists who were concerned that they would not be able to negotiate a viable contract in three years time planned to use the intervening period to either build towards conversion to private dentistry, develop their property for resale or to plan for retirement. The new ways of working made it legitimate to build private practice by working longer hours outside the contract.

Sales of premises could be exacerbated in areas where property prices were high and might encourage further retirement.

'...it will set a number of practices on the route to a very happy future... they will have the possibility of stabilising themselves for a three year period, and then they can make their choices and that's what life's about' (Dental management, November 2004).

'... a lot of dentists in their late 50s who when the new contract comes back they don't like it, they will go 'this is my excuse for retirement' or they'll become private practice' (Principal practitioner, November 2004).

\section{DISCUSSION}

This section discusses the data in the light of developments since this study was commissioned. It considers the 
uncertainty and distrust in the primary dental workforce and considers the implications for new contractual arrangements. It gives an important insight into the attitudes of dentists in an area considered traditionally as the heartland of NHS dentistry amidst the biggest changes ever to be introduced to NHS dentistry.

There have been a number of important developments since this work was commissioned in the spring of 2004. The review of Salaried Primary Dental Services was published in December 2004 and the General Dental Council again revised its guidelines on registration of dental nurses. ${ }^{12,13}$ Responsibilities for workforce training have shifted from Workforce Development Confederations to Strategic Health Authorities. The introduction of the new base contract for GDPs has been deferred twice, before coming into force in April 2006. In December 2004, the General Dental Practice Committee of the BDA declined future discussions with the Department of Health. Furthermore, the National Institute of Clinical Excellence (NICE) has published guidelines on the interval between dental recall appointments. ${ }^{14}$

In November 2004 the National Audit Office published its report Reforming NHS dentistry: ensuring effective management of risks that examined the rationale for the changes to NHS dentistry in England. ${ }^{5}$ It analysed the strengths and weaknesses of the existing system and identified the risks that might prevent the reforms from overcoming existing problems. The publication of the National Health Service (General Dental Services Contract) Regulations 2005 in December replaced the terms and conditions as outlined in the PDS scheme. ${ }^{15}$

Against this backdrop of change it is hardly surprising that uncertainty features so strongly amongst all grades and types of dentists frequently in these data. In addition, GDPs have 60 years of experience with the fee-for-item system of payment. Although many dentists welcomed a better payment structure and acknowledged that there was abuse of the payment system, the introduction of the new ways of working will inevitably cause anxiety and uncertainty. Many dentists said that their PCTs and ultimately, the Government had not provided clear information.

Uncertainty may have been particularly harmful as the legacy of the 1993 'claw back' persists and many dentists do not trust the Government. Distrust should serve as a warning and a challenge to the PCTs. The data illustrate the range of problems that are anticipated by practitioners and which have to be faced at some level. Dentistry is seen as a low priority for the Government. Until recently spending on dentistry has not kept pace with other NHS spending. In this situation dentists are moving away from NHS dentistry and private dentistry is at its highest level since the inception of the NHS. ${ }^{16}$ The Audit Commission also recognised this danger. ${ }^{5}$

Dentists traditionally are independent contractors to the NHS unlike other NHS staff who are a captive workforce. As a result local PCT staff have invested considerable effort in smoothing the move to new GDP contracts and yet uncertainty featured very prominently in the data. It is difficult to assess whether this uncertainty is unavoidable or whether more could be done to reassure dentists about the transition. However, it has been difficult for the PCTs who had to respond instantly to changes of policy. It may be valuable in future to release national policy well ahead of implementation so that PCTs have time to plan the necessary arrangements and consult externally on change management.

Dentists' lack of confidence with the new ways of working suggests that they need more information and training. They may need guidance on working more efficiently under the new contract to increase access to care whilst at the same time providing optimal individual patient care.

However, in some PCTs early conversion to PDS may have rendered such training unnecessary. Despite the reservations and uncertainty evident in these data regarding the new arrangements, most dental practitioners in South Yorkshire had joined PDS by January 2005 (at least one year ahead of the introduction of the new contract nationally) (J. Green, personal communication). However, the introduction of units of dental activity (UDAs) into this contract has been interpreted as a return to the treadmill so that these developments could be seen as confirming some of the scepticism expressed by some participants in this study. ${ }^{15,17,18}$

'...if that is what the PDS is going to be... it will be a great improvement on what the NHS are desperate to provide... it all goes back to this going back to a new treadmill and the points system and how can you turn round and say 'this is what we want' but then, 'but you have to keep your productivity up, you're only allowed a drop of 10\%'. It's, they're giving with one hand and taking away with the other, and it could be so good but it won't be because they're scared of getting conned' (Vocational trainee, October 2004).

The Audit Commission reported that patients treated under remuneration systems other than piecework had 10\% fewer treatments with no discernable impact on their oral health. ${ }^{5}$ Thus major goals are to ensure that practitioners adopt the new ways of working within the NHS, that the existing PDS contracts are successfully renegotiated and that the new arrangements can be harnessed to increase access. The GDPs' negative response to the introductions of the UDAs seems to be related to the way it has been handled rather than a reluctance to monitoring as many expressed that there was a need for monitoring within the new contract.

Dentists' need for information may also be assuaged by the publication of guidelines and the forthcoming clinical pathways for general dental practice. These guidelines may also allow for the evidence base of dentistry to increase effectiveness and efficiency. However, some practitioners said that their prescribing was already compatible with the recent NICE Guidelines on recall intervals. ${ }^{14}$ It may be some time before the benefits of the new payment system are evident. Dentists were also concerned with monitoring arrangements in future and requested clear guidance on what form they might take. It is likely that the new ways of payment and monitoring systems may have more effect on access and care than clinical guidelines.

The stated aim of the Department of Health's NHS dentistry: delivering change 1 was 'to build an NHS dental service that:

- offers access to high quality treatment for patients when they need to see a dentist

- focuses on preventing disease so that everyone, and in particular children can enjoy healthy teeth for life; and

- gives a fair deal to dentists and their teams and improves their working lives.' 
The first of these targets implies an intention to meet the needs of the community. Accordingly PCTs are tasked with commissioning services to meet local needs. The Audit Commission noted that NHS dentistry had contributed to improved oral health but needed to be more responsive. ${ }^{5}$ Whilst some dentists recognised that the service should respond to local need, the over-riding interest of most participants was individual patient care. A major challenge ahead is to reconcile these two perspectives. As one participant put it:

'The Government's priority is access; the dental professions' priority is care. And I don't think the two will ever meet.' (Vocational trainee, October 2004).

The implications of this collision of perspectives are profound. Recognising this collision is not to blame dentists. Their perspective derives from a training that focuses predominantly on the technical provision of individual items of treatment to individual patients. This training was reinforced by a payment system that has rewarded a high volume service that is most remunerative in areas of high demand. Income from more complex private treatments (which they enjoy doing) is also likely to be greater in affluent areas. GDPs invest their own funds in their practices and it can be difficult for them to sell their practices in deprived areas.

There is potential for new ways of working and the loss of some dentists to private dentistry may free up capacity and resources for this purpose. A principal task along the way must be to reorient dentists towards a community perspective whilst maintaining their job satisfaction and ability to specialise. PCTs may need to be creative in offsetting these activities against UDAs but this will be within the constraints of their requirements to fulfil patient charge revenue obligations.

\section{CONCLUSIONS}

The number of developments since this study was commissioned mean that the data require careful interpretation. This study is a snapshot of a rapidly moving situation.

There is a need for greater clarity and openness. Practitioners would welcome transparent information from the Department of Health that outlined its plans for dentistry, about the appropriate level of service to be delivered in their contracts and would like to understand the consequences of failing to meet those contracts. They also expect them to provide clear guidance to PCTs, dental practitioners and to patients about developments beyond April 2006. To some extent recent announcements about the new contract have provided this information but the changes are rapid and dentists may need more support if they are to adopt them.

Evaluation of the new ways of working will also need to reflect their intended outcomes other than simple activity measures. The PCTs and dental care providers should acknowledge their different perspectives in order to develop the new ways of working.

The authors would like to thank John Green, Peter Bateman, John Lenton, Barry Gibson and Zoe Marshman for their advice and support, and to express their gratitude for the participation of the dental practitioners in the study. This work was funded by the South Yorkshire Workforce Development Confederation.

1. Department of Health. NHS dentistry: options for change. London: Department of Health, 2002.

2. The House of Commons. Health and social care bill. HC 127, 2003.

3. Department of Health. NHS dentistry: delivering change. Report by the Chief Dental Officer (England). London: Department of Health, July 2004.

4. The House of Commons. NHS dentistry reforms. Notice of written ministerial statement. January 2005.

5. National Audit Office. Reforming NHS dentistry: ensuring effective management of risks. HC 25 Session 2004-2005. London: The Stationery Office, November 2004.

6. Watson M. We asked 25,000 dentists. Consultation response. BDA News 2004; 5: 17-18.

7. Kitzinger J. Qualitative research: introducing focus groups. Br Med J 1995: 311: 299-302.

8. McLafferty I. Focus groups interviews as a data collecting strategy. J Adv Nurs 2004; 48: 187-194.

9. Glaser B G. The constant comparative methods of qualitative analysis. Soc Probl 1965: 12: 436-445.

10. Pope C, Ziebland S, Mays N. Qualitative research in health care: analysing qualitative data. BrMed J 2000; 320: 114-116.

11. Ritchie J S L. Qualitative data analysis for applied policy research. The qualitative researchers companion. pp 305-330. London: Sage Publications, 2002.

12. Department of Health. Report of the Primary Care Dental Workforce Review. London: Department of Health, February 2004.

13. General Dental Council. New route to registration for dental nurses. 2004 http://www.gdc-uk.org/pcds.html\#dnreg. Accessed 28.1.05.

14. National Institute for Clinical Excellence, NHS. Dental recall. Recall interval between routine dental examinations. London: NICE, 2004.

15. Statutory instruments 3361 2005: The National Health Service (General Dental Services Contracts) Regulations 2005. London: The Stationery Office Limited, 2005.

16. UK Dental Care 2003. London: Laing \&t Buisson, 2003.

17. British Dental Association. BDA comments on the draft new GDS contract and PDS arrangements regulations, September 2005. London: BDA, 2005.

18. British Dental Association. Lester's Letter, January 2006. London: BDA, 2006 